\title{
Jane Grande-Allen Joins ABME Deputy Editors-in-Chief
}

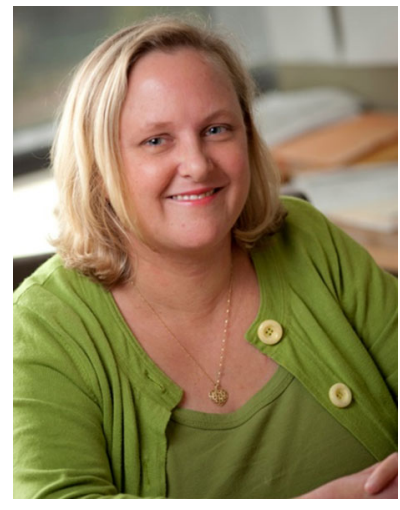

The Annals of Biomedical Engineering is pleased to announce that Jane-Grande Allen will serve as a Deputy Editor-in-Chief. In that role, she will join Kyriacos Athanasiou (Editor-in-Chief), Holly Ober (Managing Editor), and Deputy Editors-in-Chief Scott Simon and Daniel Elson. Jane Grande-Allen is the Isabel Cameron Professor of Bioengineering at Rice University. Her research group investigates the structure-function-environment relationship of heart valves through bioengineering analyses of the extracellular matrix and cell mechanobiology. Their goal in characterizing the mechanisms of heart valve remodeling is to derive novel therapies that can be used to treat patients earlier in the disease process. Her research has been funded by NIH, NSF, Pfizer, the American Heart Association, the Whitaker Foundation, and the March of Dimes, and is described in more than 100 peer-reviewed publications. Dr. Grande-Allen received a BA in Mathematics and Biology from Transylvania University in 1991 and a $\mathrm{PhD}$ in Bioengineering from the University of Washington in 1998. After performing postdoctoral research in Biomedical Engineering at the Cleveland Clinic, she joined Rice University in 2003 and was promoted to full professor in 2013. Dr. Grande-Allen is a Fellow of the American Institute of Biological and Medical Engineering, the Biomedical Engineering Society, and the American Heart Association. She served for two terms on the Board of Directors of the Biomedical Engineering Society from 2009 to 2015. In addition to her work as an associate editor of Annals of Biomedical Engineering, she also serves or has served in an associate editor/editorial board role for the journals Cardiovascular Engineering and Technology, Tissue Engineering, BCM Biotechnology, and Experimental Techniques. 